\title{
SS18-SSX Fusion Protein Expression
}

National Cancer Institute

\section{Source}

National Cancer Institute. SS18-SSX Fusion Protein Expression. NCI Thesaurus. Code C43306.

The expression of fusion proteins that result from a chromosomal aberration, $t(X ; 18)$ (p11.2;q11.2), which fuses the first 10 exons of the SS18 gene with exon six of one of three SSX genes (SSX1, SSX2 or SSX4) and is associated with synovial sarcoma. 